\title{
Outcomes and Quality of Recovery at One Year Following Percutaneous Coronary Intervention for ST Elevation Myocardial Infarction in Sri Lanka
}

Walithotage Gotabhaya Ranasinghe

National Hospital of Sri Lanka

Abi Beane ( $\nabla$ abi@nicslk.com )

Mahidol Oxford Tropical Medicine Research Unit https://orcid.org/0000-0001-7046-1580

Gamage Dona Dilanthi Priyadarshani

NICST

Thamal Dasitha Palligoda Vithanage

National Hospital of Sri Lanka

Don Dhanushka Eranga Colombage

National Hospital of Sri Lanka

Kanapathipillai Rajakanthan

Colombo South Teaching Hospital

Sanjeewa Rajapakse

Colombo North Teaching Hospital

Chandrike Janminda Ponnamperuma

National Hospital of Sri Lanka

Suneth Karunarathne

National Hospital of Sri Lanka

Ambepitiyawaduge Pubudu De Silva

National Intensive Care Surveillance, Ministry of Health, Sri Lanka

Wellaf Fransiskuge Rasika Deepal Sovis

National Hospital of Sri Lanka

Shellvacumar Sajeev

National Hospital of Sri Lanka

Vishwa Prabhath Jayasinghe

National Hospital of Sri Lanka

Constance Schultsz

Amsterdam Institute for Global Health and Development

Arjen M Dondorp

Mahidol Oxford Tropical Medicine Research Unit

Rashan Haniffa 
Mahidol Oxford Tropical Medicine Research Unit.

\section{Research article}

\section{Keywords:}

Posted Date: July 17th, 2020

DOl: https://doi.org/10.21203/rs.3.rs-41689/v1

License: (c) (1) This work is licensed under a Creative Commons Attribution 4.0 International License. Read Full License 


\section{Abstract \\ Background}

. Long term quality of recovery following percutaneous coronary intervention in Sri Lanka are unknown. We evaluated quality of recovery at one year, compliance with secondary prevention medications and access to and uptake of cardiac rehabilitation services.

\section{Methods}

. The GRACE Risk Model was used to compare predicted and actual mortality at hospital discharge and at one-year. Quality of recovery was assessed by the Seattle Angina Questionnaire. Compliance with secondary prevention therapy was assessed using international guidelines. Access to cardiac rehabilitation was assessed via telephone- administered interview.

\section{Results}

. Between April 2017 and March 2018, 699 consecutive patients underwent percutaneous coronary intervention. Mortality at one year was $13.6 \%$ (93); predicted mortality was (4.5-11\%). Functional activity was significantly worse at one year 64.4 (75.6-55.6) compared to pre-admission (100, $100-84.4)$ (Pvalue $<0.01)$. Frequency of angina was greater at one year $(80, I Q R=100-60)$, compared with 1-month post-discharge $(100[I Q R=100-80]$, P-value $<0.01)$. Stability of angina remained unchanged (median $[\mathrm{IQR}]=72[100-50])$. Patients' perceptions of treatment satisfaction were high $(P$-value < 0.01), disease perceptions worsened (P-value < 0.01). Self-perceived compliance with secondary prevention therapy ranged from $75 \%-82 \%$. Of the 362 patients followed up $146(44.5 \%)$ reported being offered the opportunity to attend cardiac rehabilitation; 128 (87.7\%) attended.

\section{Conclusions}

. Outcomes at one year were poorer than expected. Patient-reported levels of satisfaction were high, despite worsening burden of symptoms. Research is needed to better understand patients' expectations of quality of acute myocardial infarction care.

\section{Background}

Cardiovascular disease is a major cause of death globally, overtaking infectious diseases as the primary cause of death in South Asia. Delivery of high-quality cardiovascular disease care, as with other noncommunicable diseases (NCDs), places a significant burden on primary, secondary, tertiary and supportive health services. High prevalence of ischaemic cardiac disease in Sri Lanka has resulted in significant investment from the government in tertiary services, including cardiac catheterisation facilities 
to improve immediate and intermediate management of patients presenting with acute myocardial infarction (AMI). Recent studies evaluating the quality of these services have highlighted that whilst this investment has resulted in greater access to lifesaving reperfusion intervention, gaps in the quality of care across the continuum may be resulting in higher than predicted mortality at hospital discharge. Identified priorities for improving hospital outcomes include reducing delays in access to definitive treatment and improved prescription of secondary preventative therapies at discharge [1-3].

Long term recovery post AMI depends on the quality of the multidisciplinary care in hospital and after discharge. Long term outcomes are unknown in most low and middle-income country (LMIC) settings, as is, quality of recovery, access to and uptake of follow up services and patients' perceptions of their satisfaction with treatment. Understanding these patient-centred outcomes is of potentially greater importance in LMIC settings such as Sri Lanka, where patients undergoing percutaneous coronary intervention $(\mathrm{PCl})$ treatment are younger than those in Europe and their poor functional recovery and high rates of complications necessitating rehospitalisation could have devastating health and economic implications for patients and their families.

\section{Method}

\section{Aim}

We sought to evaluate long-term quality of recovery and health related experiences for AMI patients after $\mathrm{PCl}$.

\section{Setting}

Data was collected at the National Hospital of Sri Lanka (NHSL), the largest PCl-capable tertiary referral centre nationally and the country's only centre with 24-hour primary $\mathrm{PCl}$ service.

\section{Tools to evaluate the quality of recovery}

The GRACE Risk Model was used to calculate predicted mortality at hospital discharge and one year. Killip classification (severity of heart failure) was used as the risk prediction index [4]. The Seattle Angina Questionnaire (SAQ) was used to assess patient recovery at one month and one year post-discharge following primary PCI for ST elevation myocardial infarction (STEMI) $[5,6]$. SAQ is a validated tool for the measurement of five clinically important dimensions of health in patients with coronary artery disease using Likert scales [6]; physical capacity, symptom frequency, symptom stability, satisfaction with treatment, and patients' perceptions of their disease. The first four dimensions are widely accepted as important measures of quality of care $[2,7,8]$. Patients' perceptions of their disease are a description of how patients view their disease and the impact of the disease and treatment on their health and wellbeing. It is an important driver for long term treatment compliance and therefore affects the overall quality of patient recovery [9].

\section{Data collection}


Data was collected through a recently implemented AMI mHealth registry, co-designed by clinicians of the Sri Lanka STEMI Forum, which is providing a mechanism for systematic and continuous evaluation of quality of care for AMI patients and facilitating quality improvement interventions [10]. Mortality at hospital discharge, one month and one year post-procedure, along with patient's responses to the SAQ five dimensions of health were collected via telephone administered patient interviews by trained research assistants. In addition, patients were asked at the time of their hospital admission to describe their functional status (domain 1 of SAQ) prior to AMI. Events of readmission, and re-intervention were captured at hospital discharge, one month and one year. For patients who did not respond to the initial follow up call, two further calls were made. Patient responses to this evaluation were reported through the AMI registry platform. In addition, patients' self-reported adherence to secondary prevention medication (antiplatelets, statins and antihypertensives) were also reported. Finally, patients were asked to describe invitation to and uptake of cardiac rehabilitation services.

\section{Patient and public involvement (PPI)}

This study uses methods derived from international studies in which patients and the public were involved in the design. The findings of this study are accessible to patients and the public via an online platform [11]. Findings from this study are being used to design subsequent research exploring patients centered health improvement, of which PPI is key.

\section{Analysis}

Killip and GRACE scores were calculated as per the published methods $[4,12]$. Likert scale responses to the SAQ were interpreted as follows; functional limitation- the lower the score the greater the degree of functional limitation experienced; angina stability and frequency- lower scores indicate more frequent angina, and higher scores less frequent angina. Treatment satisfaction and patients' self-reported perception of their disease were interpreted in the same way. An angina frequency score of 50 indicates no change in angina frequency at the patient's most strenuous level of activity $[6,8,13]$. Prescribing of secondary prevention therapies at hospital discharge along with patients' subsequent adherence to these therapies were described at one year as a proportion of the eligible population. Wilcoxon signed-rank test was used to compare the median values for the SAQ between one month and one year post-event. The Friedman test compared domain 1 of the SAQ between three time points (primary admission, one month and one year post-event). Given that independent statistical tests performed simultaneously required comparison, Bonferroni correction was applied (significance level set at $p<0.017$ ). Stata v.11.0 (College Station, TX, USA) statistical programme was used for statistical analysis.

\section{Results}

\section{Mortality}

Between April 2017 and March 2018, 699 consecutive patients underwent PCI for STEMI and were enrolled in the registry. At one year, 13.6\% (93) patients were known to have died (predicted mortality 4.5- 
$11 \%)$. The greatest proportion of these deaths $(n=72,77.4 \%)$ were reported in the first 30 days following first admission (Fig. 1). Readmission for a primary cardiac event was reported by $12.4 \%$ of patients $(n=$ 78), with $12.2 \%(n=71)$ patients undergoing subsequent intervention for a major adverse cardiovascular event (MACE). Event-free survival at one year was $44.5 \%(n=304)$ (Table 1$)$. 
Table 1

Outcomes

\begin{tabular}{|c|c|c|}
\hline Characteristic & $\mathbf{N}$ & $\mathrm{n}(\%) *$ \\
\hline Demographics & 699 & $610(87.3)$ \\
\hline Gender, male & 693 & $52.9(11.7)$ \\
\hline \multicolumn{3}{|l|}{ Age, mean (SD), years } \\
\hline Killip class & 699 & $32(4.6)$ \\
\hline Killip class ii or iii & & $88(12.6)$ \\
\hline \multicolumn{3}{|l|}{ Killip class > iii } \\
\hline Grace score risk classification & 505 & $273(54.1)$ \\
\hline Low (49-125) & & $156(30.9)$ \\
\hline Intermediate (126-154) & & $76(15.0)$ \\
\hline High (155-319) & & $124.1(29.2)$ \\
\hline \multicolumn{3}{|l|}{ Mean score (SD) } \\
\hline In-hospital mortality & 699 & $53(7.6)$ \\
\hline Actual & & $16(2.3)$ \\
\hline Not Recorded & & $<2$ \\
\hline \multicolumn{3}{|l|}{ Predicted (\%) } \\
\hline 30 days mortality & 683 & $72(10.6)$ \\
\hline \multicolumn{3}{|l|}{ Actual } \\
\hline One year mortality & 683 & $93(13.6)$ \\
\hline Actual & & $4.5-11.0$ \\
\hline \multicolumn{3}{|l|}{ Predicted (\%) } \\
\hline MACE at one year & 630 & $78(12.4)$ \\
\hline Readmission within one year & 630 & $77(12.2)$ \\
\hline One or more intervention & 683 & $304(44.5)$ \\
\hline \multicolumn{3}{|l|}{ Event free survival at one year } \\
\hline Rehabilitation services & 630 & $146(23.2)$ \\
\hline Offered access to cardiac rehabilitation services & 146 & $128(87.7)$ \\
\hline Attended cardiac rehabilitation services & & \\
\hline
\end{tabular}




\begin{tabular}{|l|}
\hline Characteristic \\
*Unless otherwise defined in the characteristic column.
\end{tabular}
Quality of recovery at one year

Recruitment and loss to follow up are described in Fig. 2. The SAQ was completed at one year by $57.5 \%$ $(\mathrm{n}=362)$ of patients (Table 2). Median physical functioning at one year was 64.4 (IQR = 75.6-55.6) with $72.9 \%(n=264)$ of patients reporting ongoing physical limitation at one year, including walking short distances, washing and dressing. Patient satisfaction with treatment was high (median 88.2, IQR = 94.176.5). Patients reported ongoing concern about their disease and its impact on their general health status (median $50, I Q R=58.3-41.7$ ). The results of the SAQ at one month and at one year are presented in Table 2. 
Table 2

Seattle Angina Questionnaire for patients on admission, at one month and one year

\begin{tabular}{|c|c|c|c|}
\hline Seattle Angina Score & $\begin{array}{l}\text { On } \\
\text { admission } \\
\begin{array}{l}\mathrm{N}=507, \mathrm{n} \\
(\%)^{*}\end{array}\end{array}$ & $\begin{array}{l}\text { One month } N=410 \text {, } \\
n(\%)^{*}\end{array}$ & $\begin{array}{l}\text { One year } \mathrm{N}=362, \\
\mathrm{n}(\%)^{\star}\end{array}$ \\
\hline Physical limitation, median (IQR) & $100(100-$ & $91.1(100-82.2)$ & $64.4(75.6-55.6)$ \\
\hline Minimal (75-100) & & $354(86.3)$ & $98(27.1)$ \\
\hline Mild (50-74) & $448(88.4)$ & $37(9.0)$ & $202(55.8)$ \\
\hline Moderate (25-49) & $40(9.0)$ & $7(1.7)$ & $54(14.9)$ \\
\hline Severe $(0-24)$ & & $12(2.9)$ & $8(2.2)$ \\
\hline Angina stability, median (IQR) & - & $100(100-75)$ & $75(100-50)$ \\
\hline Minimal (75-100) & & 374 (91.2) & $197(54.4)$ \\
\hline Mild (50-74) & & $29(7.1)$ & $123(34.0)$ \\
\hline Moderate (25-49) & & $7(1.7)$ & $30(8.3)$ \\
\hline Severe $(0-24)$ & & $0(0.0)$ & $12(3.3)$ \\
\hline Angina frequency, median (IQR) & - & $100(100-80)$ & $80(100-60)$ \\
\hline Much better (76-100) & & $370(90.2)$ & $201(55.5)$ \\
\hline Slightly better (51-75) & & $30(7.3)$ & $83(22.9)$ \\
\hline Unchanged (50) & & $1(0.2)$ & $48(13.3)$ \\
\hline Slightly worse (25-49) & & $7(1.7)$ & $23(6.4)$ \\
\hline Much worse (0-24) & & $2(0.5)$ & $7(1.9)$ \\
\hline Treatment satisfaction, median (IQR) & - & $76.5(88.2-70.6)$ & $88.2(94.1-76.5)$ \\
\hline Completely satisfied (75-100) & & $275(67.1)$ & $287(79.3)$ \\
\hline Somewhat to mostly satisfied (50-74) & & $112(27.3)$ & $56(15.5)$ \\
\hline $\begin{array}{l}\text { Somewhat dissatisfied to not satisfied } \\
\text { at all }(0-49)\end{array}$ & & $23(5.6)$ & $19(5.2)$ \\
\hline
\end{tabular}




\begin{tabular}{|llll|}
\hline Seattle Angina Score & $\begin{array}{l}\text { On } \\
\text { admission } \\
\mathbf{N = 5 0 7 , n} \\
(\%)^{*}\end{array}$ & $\begin{array}{l}\text { One month } \mathbf{N = 4 1 0 ,} \\
\mathbf{n}(\%)^{*}\end{array}$ & $\begin{array}{l}\text { One year } \mathbf{N}=\mathbf{3 6 2}, \\
\mathbf{n}(\%)^{*}\end{array}$ \\
\hline Disease perception, median (IQR) & - & $75(83.3-58.3)$ & $50(58.3-33.3)$ \\
Excellent (75-100) & $259(63.2)$ & $11(3.0)$ \\
Good (50-74) & $109(26.6)$ & $187(51.7)$ \\
Fair (25-49) & $38(9.3)$ & $132(36.5)$ \\
Poor (0-24) & $4(1.0)$ & $32(8.8)$ \\
\hline *Unless otherwise specified under the Seattle Angina Questionnaire column. & \\
\hline
\end{tabular}


Table 3

Comparisons of responses for patients who reported SAQ at all relevant time points.*

\begin{tabular}{|c|c|c|c|}
\hline Characteristics & $\begin{array}{l}\text { AMI } \\
(\mathrm{N}=275) \\
\text { Median (IQR) }\end{array}$ & $\begin{array}{l}\text { Primary PCl ( }=182) \\
\text { Median (IQR) }\end{array}$ & $\begin{array}{l}\text { Secondary PCl }(\mathrm{N}=93) \\
\text { Median (IQR) }\end{array}$ \\
\hline Physical limitation ${ }^{\star \star}$ & $100(100-80.0)$ & $100(100-80.0)$ & $100(100-82.2)$ \\
\hline On admission & $91.1(100-82.2)$ & $91.1(100-82.2)$ & $93.3(100-80.0)$ \\
\hline $\begin{array}{l}\text { One month } \\
\text { One year }\end{array}$ & $64.4(77.8-55.6)$ & $64.4(76.7-55.6)$ & $66.7(77.8-55.6)$ \\
\hline $\begin{array}{l}\text { Angina stability } \\
\text { One month } \\
\text { One year }\end{array}$ & $\begin{array}{l}75(100-75) \\
75(100-50)\end{array}$ & $\begin{array}{l}75(100-75) \\
75(100-50)\end{array}$ & $\begin{array}{l}75(100-75) \\
75(100-50)\end{array}$ \\
\hline $\begin{array}{l}\text { Angina frequency } \\
\text { One month } \\
\text { One year }\end{array}$ & $\begin{array}{l}90(100-80) \\
70(100-50)\end{array}$ & $\begin{array}{l}90(100-80) \\
60(100-50)\end{array}$ & $\begin{array}{l}100(100-90) \\
80(100-50)\end{array}$ \\
\hline $\begin{array}{l}\text { Treatment satisfaction } \\
\text { One month } \\
\text { One year }\end{array}$ & $\begin{array}{l}76.5(88.2-70.6) \\
88.2(94.1-76.5)\end{array}$ & $\begin{array}{l}76.5(88.2-70.6) \\
88.2(94.1-76.5)\end{array}$ & $\begin{array}{l}76.5(88.2-70.6) \\
88.2(94.1-76.5)\end{array}$ \\
\hline $\begin{array}{l}\text { Disease perception } \\
\text { One month } \\
\text { One year }\end{array}$ & $\begin{array}{l}75(83.3-58.3) \\
50(58.3-41.7)\end{array}$ & $\begin{array}{l}75(83.3-58.3) \\
50(58.3-41.7)\end{array}$ & $\begin{array}{l}75(91.7-58.3) \\
50(66.7-41.7)\end{array}$ \\
\hline \multicolumn{4}{|c|}{$\begin{array}{l}\text { *All results were significant when compared to the previous time point (see Additional file } 1 \text { for the } \\
\text { tests of significance). } \\
\text { **For this result AMI }(N=260) \text {, Primary PCI }(N=172) \text { and Secondary PCI }(N=88) \text {. }\end{array}$} \\
\hline
\end{tabular}

\section{Progression of symptoms}

Functional activity worsened over the one year period ( $p<0.01$, Additional File 1 ). Burden of angina (stability and frequency) was the same or worse when compared to time of primary admission to hospital for $48.5 \%(n=169)$ of patients (Table 3$)$. Frequency of angina was significantly greater $(p<0.01)$ at one year, whilst stability of angina remained unchanged $(p<0.01)$. Patients' perceptions of their satisfaction with treatment improved between the two time points, $(p<0.01)$, but patients' perceptions of their disease and the relative constraint on their health and wellbeing worsened $(p<0.01)$. All tests were significant when compared to previous time points for both primary and secondary PCl populations. 


\section{Compliance with secondary prevention medications and access to cardiac rehabilitation services}

Self-perceived compliance at one year for secondary prevention therapy was 298 (82.3\%) for antihypertensives, 277 (76.5\%) for statins and $297(82.0 \%)$ for antiplatelets. Of those patients followed up at one year, $146(44.5 \%)$ reported being offered the opportunity to attend cardiac rehabilitation, 128 $(87.7 \%)$ patients did so on at least one occasion.

\section{Discussion}

\section{Long-term quality of recovery}

This study reports higher than predicted mortality at one year post AMI in this relatively young, low risk cohort of patients. The causes of death in this cohort are unknown and accessing health records and death certificates in this setting is, as with many countries where harmonised health and social records are not available, not feasible. However, given the survivors reported an increasing burden of symptoms, associated with ongoing ischemia, it may be reasonable to attribute cardiac causes to at least a proportion of deaths reported [14]. The findings here regarding non-concordance with secondary prevention therapy and limited opportunity to attend cardiac rehabilitation may further predispose this population to subsequent adverse cardiac outcomes. Whilst the greatest risk of mortality for this cohort was within the first 30 days following infarct, and may be attributable to the limitations in prehospital and acute care described previously in this setting [10], this study identifies gaps in the post-acute phase quality of care, which may be further contributing to the poor long term survival [15-18].

Noncompliance with secondary prevention medication and inequity in access to cardiac rehabilitation may be contributing to the progressive worsening physical function and angina reported by patients here. Whilst research on long term outcome after AMI is notably absent from the region, studies undertaken in high income settings has described how poor functional recovery post AMI can result in economic instability and loss of employment for patients. Furthermore, poor functional recovery may predispose patients to a worsening sequela of comorbidities and their complications $[9,16,19]$. In this setting, where continuity of care between primary and secondary healthcare services is limited, such complications of chronic disease may go undetected and may have devastating effects for patients $[2,20]$.

The worsening disease perception described by patients in this study may be further contributing to the poor quality of recovery. Negative disease perception, which may manifest as anxiety and depression for patients, is in itself detrimental to mental health and wellbeing $[13,15]$. However, poor mental health is also known to limit patient's participation in physical rehabilitation, hinder patients' concordance with secondary polytreatment and inhibit patients willingness to engage in physical exercise and healthy eating. Importantly, however, these negative sequelae of patient health status post AMI are amenable to intervention [21]. Interventional studies undertaken in Europe to improve access and attendance to post AMI cardiac rehabilitation and to improve concordance with secondary prevention medications through 
patient education and multi-disciplinary led follow-up clinics were shown to have high levels of patient engagement and were shown to lead to a reduction in long term mortality [18, 22, 23]. Given the high uptake of cardiac rehab services from patients who were offered in this setting, similar interventions may be successful.

\section{Loss to study follow up and impact on evaluating the quality of care}

Loss to follow up of patient outcomes in this study was $20.1 \%$ at one year for mortality $(47.2 \%$ for quality of recovery) and may be masking significantly higher mortality. In this study, expired mobile phone numbers provided by patients for follow up was the main reason for failure to contact patients after discharge and may point to survival bias [24]. This hypothesis is supported by the minimal loss to follow up once initial telephone contact was made. It is, however, not uncommon for follow up studies of AMI patients in high income healthcare settings to describe loss to follow up as high as $50 \%$ [22]. In LMIC settings the challenges are often greater; absence of a unique patient identifiers in health systems, no national registry of patients' admission to healthcare facilities, low penetrance of landline telephones and relatively mobile urban populations, all of which hampers efforts to follow patients $[1,13,22]$.

\section{Disconnect between patient satisfaction and quality of care}

Patients reported consistently high levels of satisfaction despite worsening symptoms and perceptions of their disease. Our previous evaluation of the in-hospital care for AMI patients in this setting using European Society of Cardiology guidelines reported median overall compliance to six domains of quality of in-hospital care for this cohort of patients at just $42 \%[13,25]$. There is the potential mismatch between what patients consider good quality care and that of the European Society of Cardiology guidelines, and raises questions of how patients' perceived quality of healthcare in this setting and their priorities when seeking treatment $[20,26,27]$. Patient expectations of care can be lowered by lack of exposure to higherquality services, lack of knowledge about what constitutes high quality care (health literacy) and a general lack of information providing feedback to communities about health service provision. Low patient and family expectations of health services is problematic as it may perpetuate poor quality care and may delay efforts by clinicians such as those here from prioritising improvements in services [2830].

\section{Recommendations}

Providing discharge follow up and cardiac rehabilitation services may be feasible in this setting and is already being offered in some tertiary settings. Information on the quality and timing of these services, as well as the barriers and facilitators to patient engagement with such services is needed. Further understanding of the biases influencing patients' perceptions of satisfaction, and what communities value in their health care is urgently needed, given the increasing focus on patient values as a measure of quality of care. Qualitative work to understand patient values for quality of care and satisfaction is planned by this collaboration. 


\section{Conclusions}

This study highlights poor long-term outcomes after PCl in a relatively young, low risk population. Investment in health system infrastructure to evaluate long term patient centred outcomes has provided stakeholders with measurable targets for improvement. Investment in $\mathrm{PCl}$ services in the region is commendable, however further investment in access to services across the continuum of care is now needed. Exploring the whole multicomponent processes of care including patients' health literacy, and greater investment in services to support follow up and rehabilitation of patients after discharge may be important considerations in future health services planning. Investment in pragmatic research into the determinants of value-based care is needed.

\section{Abbreviations}

AMI

acute myocardial infarction; IQR:interquartile range; LMIC:Iow and middle-income country; MACE:major adverse cardiovascular event; NCD:non-communicable diseases; NHSL:National Hospital of Sri Lanka; PCl:percutaneous coronary intervention; PPI:patient and public involvement; SAQ:Seattle Angina Questionnaire; STEMI:ST-elevation myocardial infarction.

\section{Declarations}

\section{Ethics, consent and permissions}

All patients provided informed verbal consent to participate in this study as the data was collected by telephone administered patient interviews. Ethical approval for the study, including the process of informed verbal consent, was obtained from the University of Colombo Research and Ethics committee (EC-17-059).

\section{Availability of data}

All data generated or analysed during this study are included in this published article and its supplementary information files.

\section{Competing interests}

The authors have no competing interest to declare.

\section{Funding}

This study was funded by Network for Improving Critical Care System and Training and the Sri Lanka STEMI Forum as part of ongoing projects to improve the quality of acute myocardial infarction care. The funding sources of the study provided access to the AMI registry and data, but did not dictate the study design; the writing of the report; or the decision to submit the article for publication. 
Author's contributions

Conception or design of the work: WGR, AB, GDDP, CS, AMD and RH. Data curation: GDDP, AB and WGR. Data analysis and interpretation: $A B, G D D P$ and WGR. Drafting the article: $A B, W G R$ and GDDP. Critical revision of the article: All authors. Final approval of the version to be published: All authors.

\section{Acknowledgements}

We would like to acknowledge the collaborators for their clinical intellectual contributions and the families and patients that so generously provided important insights into their experiences of AMI care. The opportunity to follow up patients at one year following treatment is greatly important for improving the quality of care and directing future resource investment.

\section{References}

1. Galappatthy P, Bataduwaarachchi VR, Ranasinghe P, Galappatthy GKS, Wijayabandara M, Warapitiya DS, et al. Management, characteristics and outcomes of patients with acute coronary syndrome in Sri Lanka. Heart. 2018;104:1424-31.

2. Kruk ME, Gage AD, Joseph NT, Danaei G, García-Saisó S, Salomon JA. Mortality due to low-quality health systems in the universal health coverage era: a systematic analysis of amenable deaths in 137 countries. Lancet. 2018;392:2203-12.

3. Beane A, De Silva AP, Athapattu PL, Jayasinghe S, Abayadeera AU, Wijerathne M, et al. Addressing the information deficit in global health: Lessons from a digital acute care platform in Sri Lanka. BMJ Global Health. 2019;4:1-7.

4. Killip T 3rd, Kimball JT. Treatment of myocardial infarction in a coronary care unit. A two year experience with 250 patients. Am J Cardiol. 1967;20:457-64.

5. Balestroni G, Bertolotti G. EuroQol-5D (EQ-5D): an instrument for measuring quality of life. Monaldi Arch Chest Dis. 2012;78:155-9.

6. Spertus JA, Winder JA, Dewhurst TA, Deyo RA, Prodzinski J, McDonell M, et al. Development and evaluation of the Seattle Angina Questionnaire: a new functional status measure for coronary artery disease. J Am Coll Cardiol. 1995;25:333-41.

7. Ho PM, Spertus JA, Masoudi FA, Reid KJ, Peterson ED, Magid DJ, et al. Impact of medication therapy discontinuation on mortality after myocardial infarction. Arch Intern Med. 2006;166:1842-7.

8. Krumholz HM, Merrill AR, Schone EM, Schreiner GC, Chen J, Bradley EH, et al. Patterns of hospital performance in acute myocardial infarction and heart failure 30-day mortality and readmission. Circ Cardiovasc Qual Outcomes. 2009;2:407-13.

9. Rasmussen JN, Chong A, Alter DA. Relationship between adherence to evidence-based pharmacotherapy and long-term mortality after acute myocardial infarction. JAMA. 2007;297:17786. 
10. Ranasinghe WG, Beane A, Vithanage TDP, Priyadarshani GDD, Colombage DDE, Ponnamperuma CJ, et al. Quality evaluation and future priorities for delivering acute myocardial infarction care in Sri Lanka. Heart. 2020;106:603-8.

11. NICST. Network for Improving Critical care Systems and Training. Network for Improving Critical care Systems and Training. 2020. https://nicst.com/. Accessed 29 Jun 2020.

12. Fox KAA, FitzGerald G, Puymirat E, Huang W, Carruthers K, Simon T, et al. Should patients with acute coronary disease be stratified for management according to their risk? Derivation, external validation and outcomes using the updated GRACE risk score. BMJ Open. 2014;4:e004425. doi:10.1136/bmjopen-2013-004425.

13. Faridi KF, Peterson ED, McCoy LA, Thomas L, Enriquez J, Wang TY. Timing of First Postdischarge Follow-up and Medication Adherence After Acute Myocardial Infarction. JAMA Cardiol. 2016;1:14755.

14. Sri Lanka Department of Health. Annual Health Bulletin 2012. Sri Lanka Department of Health. http://www.health.gov.lk/. Accessed 3 Oct 2019.

15. Huber K, Gersh BJ, Goldstein P, Granger CB, Armstrong PW. The organization, function, and outcomes of ST-elevation myocardial infarction networks worldwide: current state, unmet needs and future directions. Eur Heart J. 2014;35:1526-32.

16. Kripalani S, Theobald CN, Anctil B, Vasilevskis EE. Reducing hospital readmission rates: current strategies and future directions. Annu Rev Med. 2014;65:471-85.

17. Lee JH, Yang DH, Park HS, Cho Y, Jeong MH, Kim YJ, et al. Suboptimal use of evidence-based medical therapy in patients with acute myocardial infarction from the Korea Acute Myocardial Infarction Registry: prescription rate, predictors, and prognostic value. Am Heart J. 2010;159:1012-9.

18. Ventura M, Belleudi V, Sciattella P, Di Domenicantonio R, Di Martino M, Agabiti N, et al. High quality process of care increases one-year survival after acute myocardial infarction (AMI): A cohort study in Italy. PLoS One. 2019;14:e0212398.

19. Ho PM, Luther SA, Masoudi FA, Gupta I, Lowy E, Maynard C, et al. Inpatient and follow-up cardiology care and mortality for acute coronary syndrome patients in the Veterans Health Administration. Am Heart J. 2007;154:489-94.

20. Roder-DeWan S, Gage AD, Hirschhorn LR, Twum-Danso NAY, Liljestrand J, Asante-Shongwe K, et al. Expectations of healthcare quality: A cross-sectional study of internet users in 12 low- and middleincome countries. PLoS Med. 2019;16:e1002879.

21. Sullivan AL, Beshansky JR, Ruthazer R, Murman DH, Mader TJ, Selker HP. Factors associated with longer time to treatment for patients with suspected acute coronary syndromes: a cohort study. Circ Cardiovasc Qual Outcomes. 2014;7:86-94.

22. Solberg TK, Sørlie A, Sjaavik K, Nygaard ØP, Ingebrigtsen T. Would loss to follow-up bias the outcome evaluation of patients operated for degenerative disorders of the lumbar spine? A study of responding and non-responding cohort participants from a clinical spine surgery registry. Acta Orthop. 2011;82:56-63. 
23. Calman NS, Hauser D, Chokshi DA. "Lost to Follow-up": The Public Health Goals of Accountable Care. Arch Intern Med. 2012;172:584-6.

24. Lodi-Junqueira L, Ribeiro AL. Tackling acute coronary syndrome in low-income and middle-income countries. Heart. 2018;104:1390-1.

25. https://academic.oup.com/eurheartj/article-abstract/39/2/119/4095042.

26. Bowling A, Rowe G, McKee M. Patients' experiences of their healthcare in relation to their expectations and satisfaction: a population survey. J R Soc Med. 2013;106:143-9.

27. Conway T, Willcocks $S$. The role of expectations in the perception of health care quality: developing a conceptual model. Int J Health Care Qual Assur Inc Leadersh Health Serv. 1997;10:131-40.

28. Bowling A, Rowe G, Lambert N, Waddington M, Mahtani KR, Kenten C, et al. The measurement of patients' expectations for health care: a review and psychometric testing of a measure of patients' expectations. Health Technol Assess. 2012;16:i - xii, 1-509.

29. Bleich SN, Ozaltin E, Murray CKL. How does satisfaction with the health-care system relate to patient experience? Bull World Health Organ. 2009;87:271-8.

30. 30 .

\section{Figures}

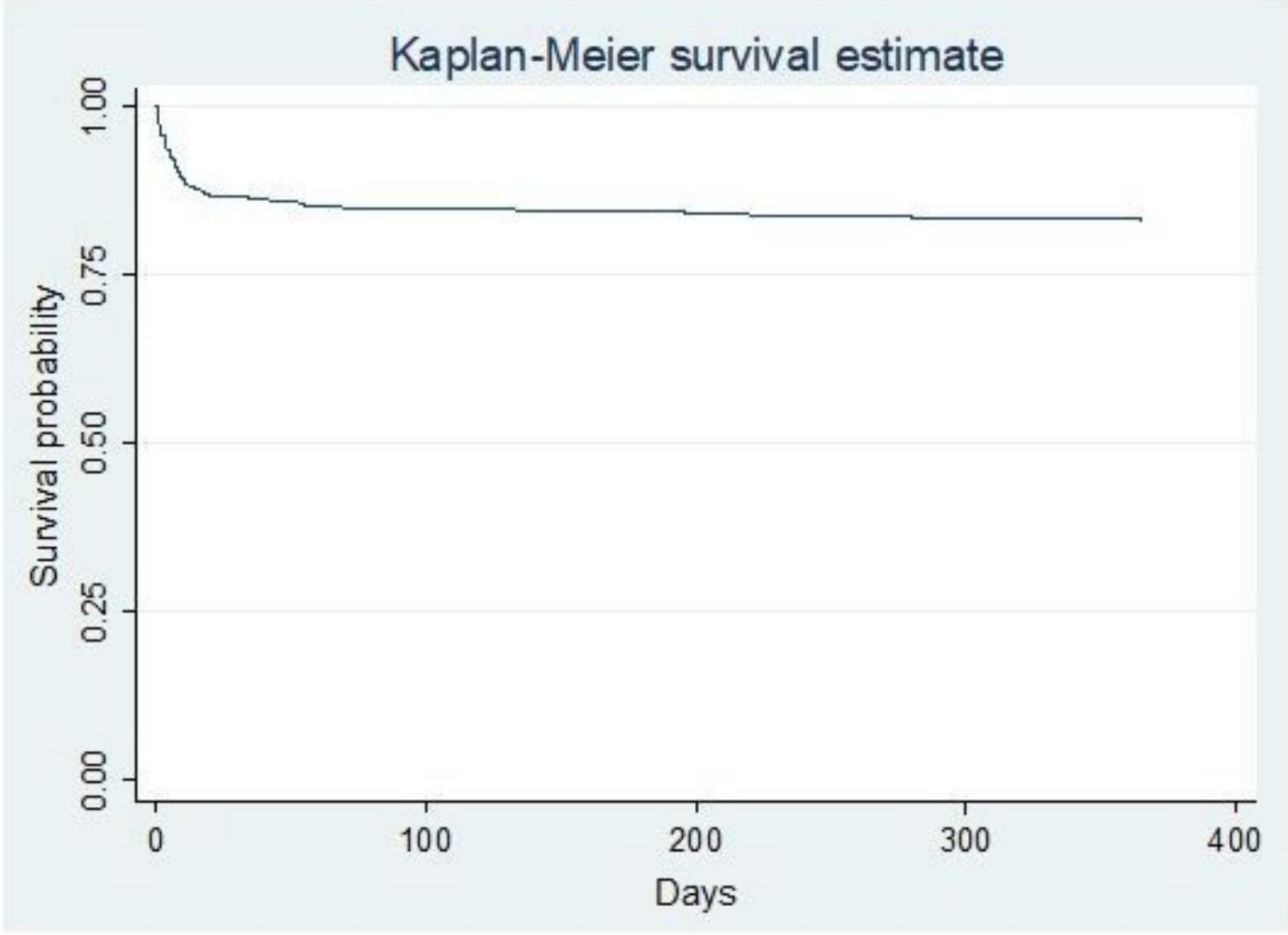

\section{Figure 1}

Plot of Kaplan-Meier survival analysis up to one year estimated after $\mathrm{PCl}$. 


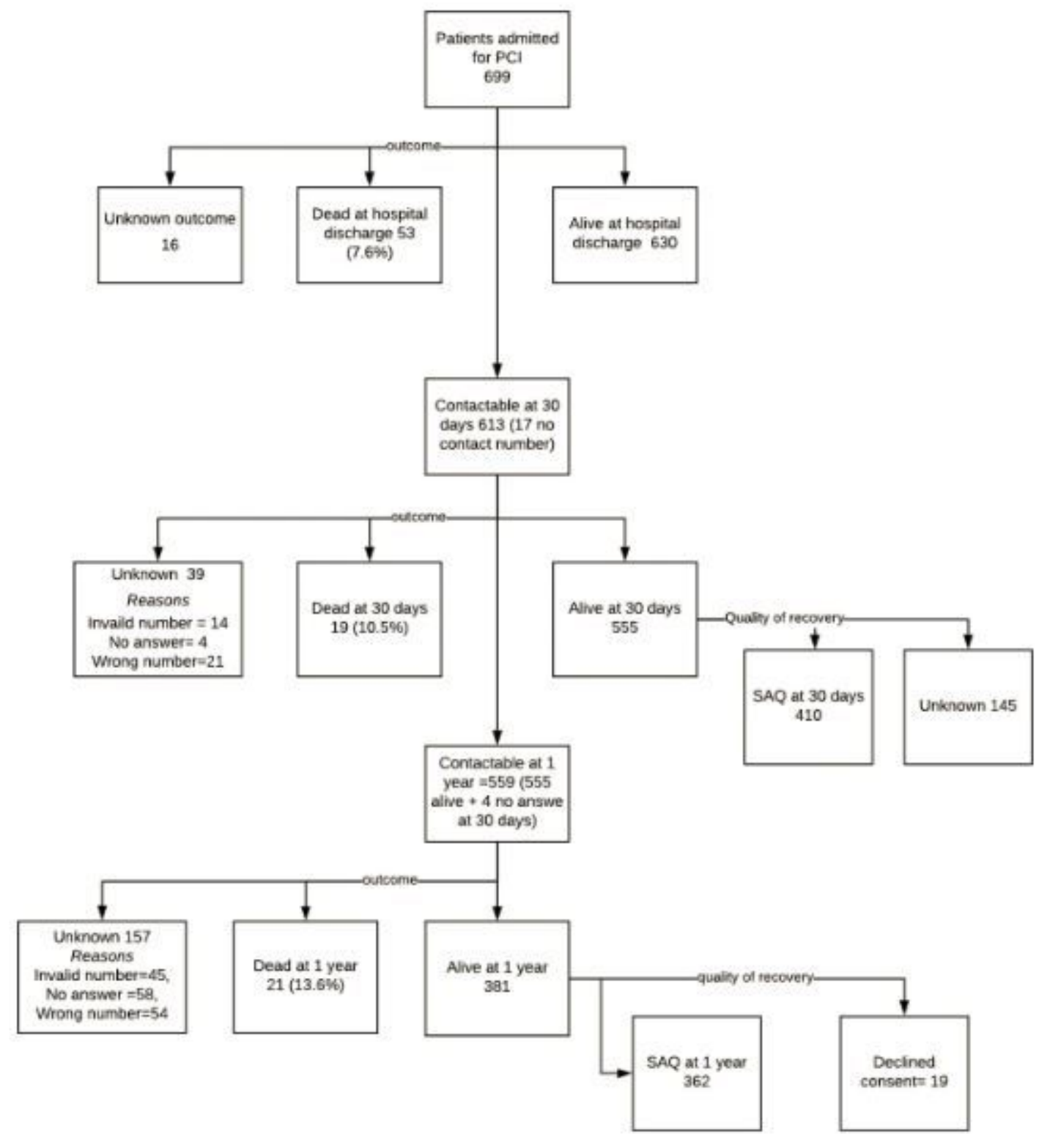

Figure 2

Recruitment, outcomes and loss to follow up of patients recruited through the AMI platform.

\section{Supplementary Files}

This is a list of supplementary files associated with this preprint. Click to download.

- AdditionalFile1.docx 